\title{
THE ROLE OF THE CARGO CONSOLIDATION CENTER IN URBAN LOGISTICS SYSTEM
}

\author{
M. JACYNA \\ Department of Logistics and Transport Systems, Warsaw University of Technology, Poland.
}

\begin{abstract}
The paper presents some results of research on city logistics systems performed within the frame of the project 'The model of logistics system of Poland as a way to transport co-modality in the EU'. The main objective of this paper is to present problems of logistics services for urban agglomeration by using Cargo Consolidation Centers. The general form of two-step logistics services for the city provided by Cargo Consolidation Centers and City Transshipment Hubs are presented. The elements of the logistics system, including CCC, supplying goods to customers located in the cities and also relationships between them were identified. Two-stage system was enriched by appropriate optimization task formulated to minimize logistics servicing costs. Practical application of the proposed approach was presented on the example of selected district of Warsaw.
\end{abstract}

Keywords: cargo consolidation center, city logistics, urban logistics system model, urban transshipment hubs.

\section{INTRODUCTION}

Logistics for urban agglomeration encounter many problems due to numerous specific factors that must be taken into account for this type of areas. High population density on urban areas is one of the most important factors. For example, density in urban areas in Poland in 2009 was about 1090 person $/ \mathrm{km}^{2}$, while for countryside it was about 51 person $/ \mathrm{km}^{2}$. Such a large number of people living within a small area lead to very high density of housing development. It is connected with the expansion of road infrastructure, which is usually too weak in relation to existing situation and even more to the projected increase in urban population $[1,2]$. Moreover, quality of road infrastructure is not proper and traffic organization is unsuited to the needs. This situation is conducive to very high traffic congestion in central area of urban agglomeration during daylight hours and on the main arteries leading from the residential areas to the center during morning and afternoon. Major traffic congestion affects the quality of life in these areas. It produces effects, such as increase in $\mathrm{CO}_{2}$, particulates and other compounds harmful to humans in the air, noise levels, increase in the number of accidents and collisions, frequent acceleration and braking increase the fuel consumption and vehicles components wear and increase the stress on drivers.

Very often local authorities implement further restrictions on movement of freight vehicles to improve passenger transport and give special privileges to public transport. These actions may be effective, if they are consistently enforced. However, they cause some problems in delivering goods to urban areas - especially downtown. There are many delivery points, such as shops, restaurants, shopping centers, and public institutions located. It is important to remember that these points play an important role in the functioning their environment. They provide necessary material goods and services for those people who are living or working there and for businesses located in this area. On the one hand, city logistic aims in reducing burden associated with freight transport in urban areas, and on the other hand it aims in supporting the economic and social development of agglomerations $[3,4]$. Solutions to reduce freight traffic in urban areas are the major object of city logistic researches.

Integrated City Logistics System (ICLS) is one of the options to serve urban areas. Providing material flows with ICLS leads to reduction in freight traffic in urban areas by coordinating material flows and elimination of empty runs. The reduction of nuisance associated with the delivery of goods to a wide spectrum of customers located in the cities is the effect of coordinating material flows [5]. 


\section{CARGO FLOW RATIONALIZATION THROUGH A CARGO CONSOLIDATION CENTER}

To develop a suitable and efficient logistics system supporting city, all the expectations and needs of the city as an area of institutional and social activity must be taken into account. This requires knowledge of dependencies and relations between them. Moreover, it is necessary to investigate the impact of the surroundings on the city, so the material and information streams coming from the National Logistics System (NLS) must be known $[2,5]$. For proper determination of relations within the city, the identification of all functional areas and their specific characteristics must be done. The urban structure, among other things consists of

- production and processing plants;

- service business;

- wholesale distribution and supply;

- households, individual consumption;

- operators providing such services as courier services, express mail etc.;

- municipal utilities (water supply, heating plants, power plants, gas plants);

- network of retail outlets, supermarkets, shops; and

- science and education, culture, healthcare, catering, public safety, sport and recreation, entertainment.

While the surrounding for the urban area will be

- logistics and distribution centers, etc.;

- manufacturing companies;

- extractive industries, including agriculture;

- import and export;

- other cities and regions and their populations; and

- domestic water, gas and energy supply systems, etc.

Effective and efficient logistic services for the city depend on cooperation of all elements from the city and its surroundings, including citizens and local authorities, which may be a major catalyst for change in city logistics. According to passenger transport, fostering public transport instead of private vehicles in the critical points of the city can be a solution $[1,6,7]$. Elimination of all private vehicles from the city is impossible but a few percentage traffic decrease may be important. Changes in this case are usually placed on local authorities through establishing appropriate restrictions, allowances, and adequate infrastructure, such as Park \& Ride places.

Change in the flow of goods throughout the city is a more complicated issue. Reduction of cargo flow or move it completely beside of rush hours is not possible. Removing unnecessary transit traffic outside the city or at least outside the city center to the ring and reducing number of freight vehicles by increasing their loading space utilization should be the main direction of changes. Moreover, routes rationalization can improve transportation system as a whole and bring significant cost reduction for carriers and all entities supported by them. The only threat which should be noted at the stage of designing changes is preventing monopolization or unrealistic law-tightening logistics and transportation services throughout the city.

Agency of loading point handling and consolidating shipments is an effective way to solve problems of under-utilization of vehicles loading capacity and their excessive numbers caused by handling the same areas through a variety of competing suppliers $[2,5,8]$. This point in this article 


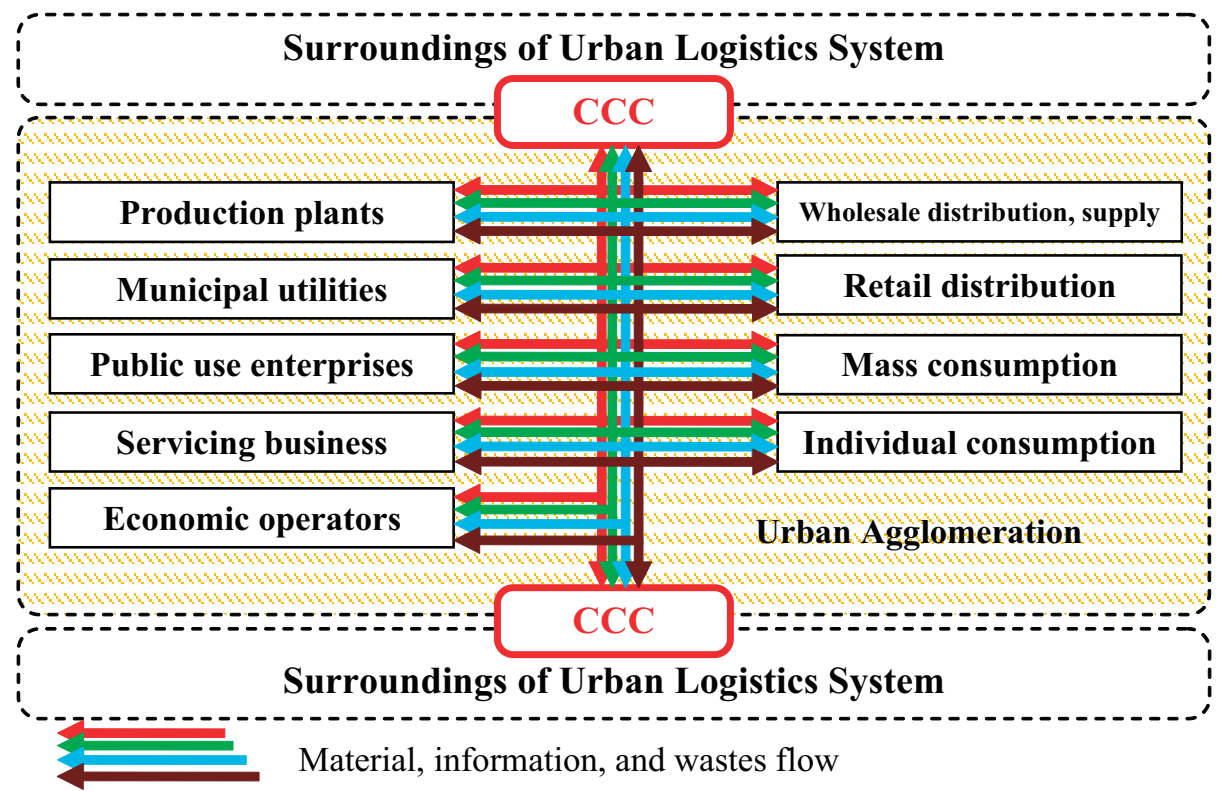

Figure 1: The model of combining CCC with ULS.

will be known as the Cargo Consolidation Center (CCC). CCC can be defined as a kind of warehouse object that is characterized by very high turnover and diverse types of material streams. The main task of this object is the reduction of nuisances of transport in urban areas. Center combines the NLS with Urban Logistics System (ULS) (Fig. 1).

\section{CARGO CONSOLIDATION CENTER IN SERVICING URBAN AGGLOMERATION}

It was assumed that $\mathrm{CCC}$, as an independent operator, provides logistics services, including transportation, material handling, storage, distribution, and order picking of goods originating from the ULS surroundings. Supplying and distribution of goods to the customers located in urban area is the function of CCC. Therefore, CCC is a warehouse object for buffering, dividing, and picking fastrotating material streams of diverse types. Manufacturing plants, retail outlets (shopping centers, specialist shops, shopping malls, etc.), and service facilities are receiving points in urban agglomerations. The receivers can be served $[2,5]$ :

- directly - the direct delivery of goods from the sender staying outside the agglomeration to the recipient located within the urban area,

- indirectly - through CCCs and Urban Transshipment Hubs (UTHs),

- in a combined way - directly or with the participation of CCC and ULS.

CCC serves material streams coming to the city from the suppliers in NLS. Their materials are combined in packages due to client's orders and supplied to the recipients in the city by vehicles designed for city traffic. Area served by each CCC is split into routes to maximize the vehicles capacity utilization and minimize the time and transportation costs. Moreover, vehicles distributing goods may also receive materials from suppliers localized in the city center and deliver it to the CCC, where they are processed as described previously. For large batches of supplies, served with 
bigger means of transport, a direct connection between NLS and ULS without CCC is possible. Mutual relations between NLS, CCC and ULS are schematically shown on Fig. 2.

In the CCC designing for a given city, the condition and type of road infrastructure outside the highly urbanized area must be considered. Possibility of supplying UTHs by vehicles with a larger capacity than those used to operate in the city must be analyzed. Sometimes it's a better solution to design two or more CCCs than transport cargos to distant UTHs. Such a solution can be used for cities that do not have ring roads or convenient through-routes.

Depending on the city size, its transportation system, and the cost, CCC can supply urban areas in one- or two-stage organization. In single-stage model, CCC is a point to which goods are supplied by the suppliers, and due to operations leading to the right consolidation, materials are delivered directly to target customers (Fig. 2b). This method can be used in smaller cities where distances to be travel are not too large. In the second way, CCC provides goods to intermediate transshipment hubs where loads are transferred to smaller vehicles and then delivered to customers (Fig. 3a).

a)

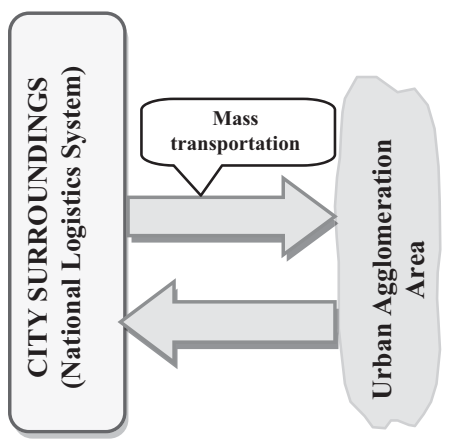

b)

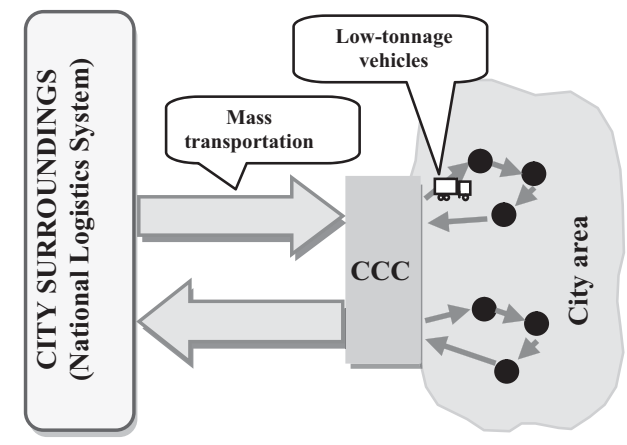

Figure 2: Graphic illustration of operating the city (a) direct; (b) indirect with usage of CCC. Source: [2].

a)

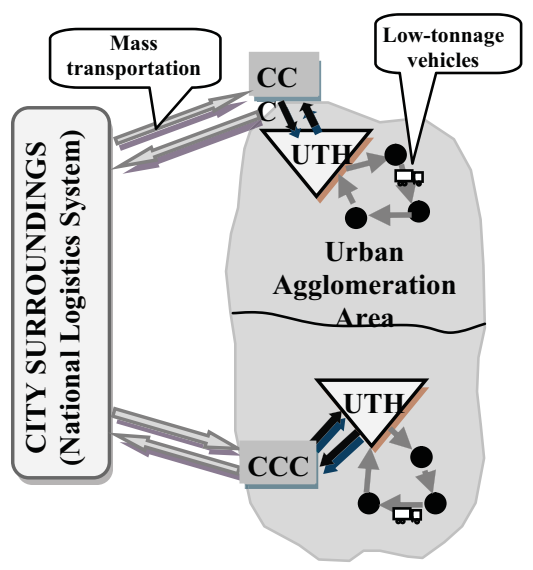

b)

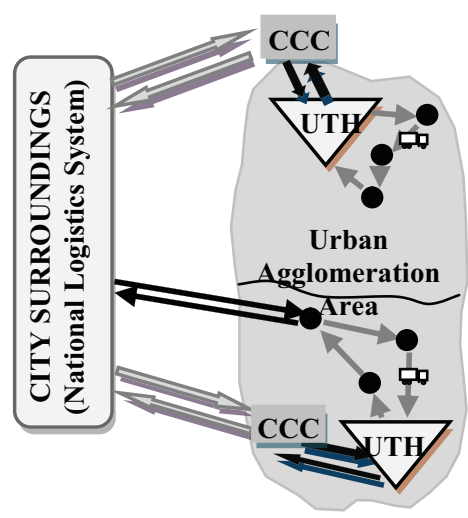

Figure 3: Graphical illustration of logistics services for a city (a) two-stage servicing system; (b) combined servicing system. Source: [2]. 
This solution should be used in larger cities where constructing additional facilities and making more operations on cargo will be more profitable than long-distance transport. These two ways of servicing city can be combined. Then those customers which are located near the CCC will be served directly without UTHs usage, while the remaining will get two-step method (Fig. 3b).

\section{CONSTRUCTING MATERIAL FLOW PROCESS \\ IN CARGO CONSOLIDATION CENTER}

$\mathrm{CCC}$ as a storage and distribution facility is characterized by very high turnover and diverse types of material streams. Depending on the model of the city logistics (see point 3 ) and the number of customers to be served in several functional areas and zones can be distinguished. The most important areas in which main activities are performed are presented below (Fig. 4):

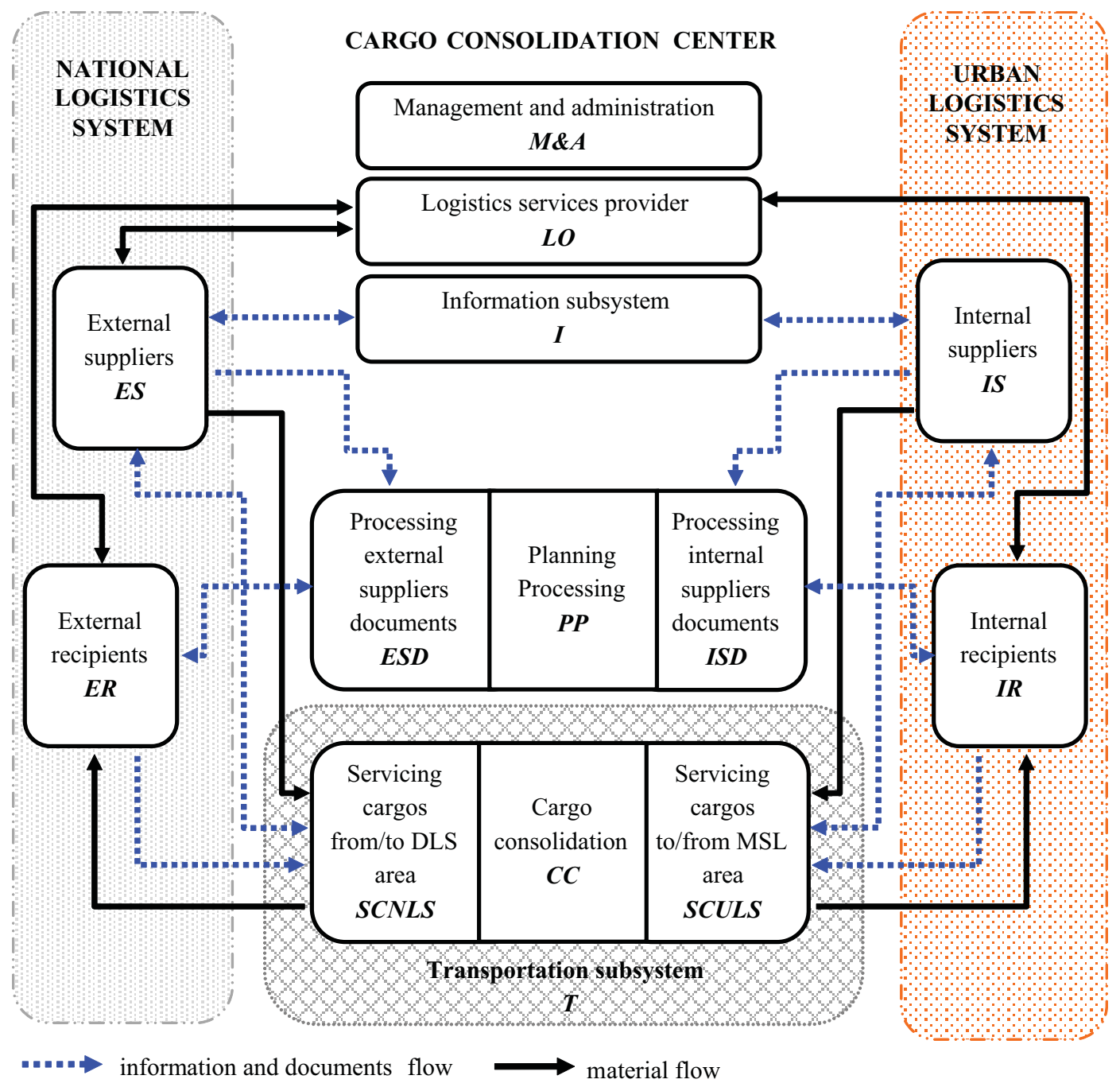

Figure 4: The overall pattern of links between different CCC areas and CCC surrounding. 
A. CCC management area including:

- external logistics operators (LO) - not having their own storage facilities and/or transport infrastructure, cooperating with a CCC as service providers acting on behalf of their clients;

- information subsystem (I) - collecting orders from NLS and ULS areas, pre-processing and sending orders to further realization in planning department;

- management and administration (M\&A) - functional area to control CCC, maintaining continuity of operations, personnel management, etc. It does not take part in material and information flow through supply chain;

B. Office area including:

- planning (PP) - plays an essential role in the structure of $\mathrm{CCC}$, has great influence on the cargo flow through the city, processes data from information subsystem to be used in cargo consolidation process;

- doing external costumers documents (ESD) - processing incoming and outgoing documents to CCC contractors from the NLS area;

- doing internal costumers documents (ISD) - processing incoming and outgoing documents to CCC contractors from the ULS area;

C. Storage area including:

- handling materials from NLS (SNLS) - receiving and shipping cargos from/to NLS, processing shipment documents and materials on warehouse entrance/exit;

- handling materials from ULS (SCULS) - receiving and shipping cargos from/to ULS, processing shipment documents and materials on warehouse entrance/exit;

- handling external and internal supplies, consolidation (CC) - maintaining cargos staying in $\mathrm{CCC}$ warehouse, proper slotting of material units in a storage areas, forming and composing units according to orders from planning department.

D. Transportation area $(\mathrm{T})$ - means carrying long-distance transport and short-distance transport in urban agglomeration for CCC. Long-distance transport can be carried by trucks or railway, if CCC has its own railway siding, or has an access to this kind of infrastructure. Fleet may be owned by the CCC or third-party companies working on behalf of the CCC. This area must be well organized and effective to provide the customers with all the services offered by the CCC in an appropriate way.

Relations between these areas area subject to many factors:

- the type of cooperation between NLS actors determined by possessed distribution network and organization of logistics of selected goods,

- cooperation of carriers providing transportation services in the area (e.g. lack of competition lowering transport costs),

- cooperation of receivers in the serviced urban area, regardless of affiliation to specific brands (retailers, catering, etc.),

- cooperation of LOs providing services to companies located in the ULS or supplying goods to them.

\section{URBAN LOGISTIC SERVICE MODEL IN RELATION WITH THE NATIONAL LOGISTICS SYSTEM}

\subsection{General assumptions}

The literature about urban logistics issues $[1,2,6,8]$ is very rich and concerns on the solutions aimed at satisfying the expectations of customers group with different needs as well as the methods of 
reduction of the truck traffic arduousness in towns. As it has already been said, the logistic service of urban agglomerations is a very complicated problem. It is the effect of high population density and the broad spectrum of consumers, which involve in overloading the road network and worsening the condition of urban roads. Limitations in the transport infrastructure development are another consequence.

Improvement in the urban transport service primarily means a reduction of commercial vehicles in the urban area. Such a reduction can be achieved, among other things, through a more effective usage of vehicles, for example, by obtaining higher average vehicle loading coefficients, reducing empty runs, etc. $[1,6,8]$. The issue of the urban area service is related to servicing disperse customers located in heavily urbanized areas. Therefore, it pertains to the problem of setting transport routes as part of the so-called Vehicle Routing Problem (VRP).

The paper presents the model of a two-stage urban logistic service system. Transition points in the system are Load Consolidation Centers (LCC) and UTHs. It has been assumed that the logistic service proceeds in the following manner:

1. Goods are delivered with high tonnage transport means (urban motor trucks [UMT]) to LCC's where the goods are unloaded. The goods come from various sources, including production companies and wholesale agents belonging to Poland's Logistic System.

2. At the LCC, goods are sorted, possibly consolidated and loaded on the so-called UMT with a capacity of up to 10 tons.

3. For each UMT-type vehicles, the departure time and service routes are set; each vehicle serves one or more UTHs.

4. At the UTH, the merchandise is reloaded to delivery vehicles (urban delivery vans [UDV] with a maximum capacity of up to 3.5 tons.

5. UDV supply indicated customers along set routes and then go to the point where another loading takes place (it is not necessarily the same UTH). When the vehicle goes back to the same hub, then the route is determined according to the Travelling Salesman Algorithm.

The urban agglomeration is divided into zones defined as service regions of respective UTHs. The routes where UMT- and UDV-type vehicles travel have been specially selected to facilitate the access to transshipment points and reduce the impact on the urban transport system and the environment.

The system operation period is described by period set $\boldsymbol{T}$, that is

$\boldsymbol{T}=\{t: t=1,2, \ldots, \bar{T}\}$. It is assumed that the planning horizon is relatively short $-\mathrm{a}$ few hours or half-a-day in most cases.

We also assume that the journey time is strictly related to traffic conditions; hence, it may change in a period of time and in a particular urban zone (e.g. traffic jams moving toward the city center during the morning rush hour, etc.). Moreover, depending on a specific time of day, possible passage routes between two points in the town may differ as a result of traffic regulations or restrictions introduced for congested urban areas.

\subsection{Description of model data}

The model developed serves the purpose of minimizing the number of vehicles in the town, especially UMTs, with the conditions met as regard the satisfying the recipients' needs (the order may not be divided between various routes). The data to be verified concern:

- transshipment points LCC and UTH and their work specificity;

- types and characteristics of the vehicles employed for the service; 
- customers' needs;

- number of times of servicing individual points and customers, depending on the type of service provided.

We assume that there are set characteristics of each of the transition points, that is, CCC and UTH with respect to the working hours and service capabilities of UMTs and urban delivery vans. Therefore, we assume that the following has been defined:

- set $\boldsymbol{C K}=\left\{L C_{c k}: c k=1,2, \ldots, \overline{C K}\right\}$ - numbers of the CCCs, where the goods are sorted and consolidated;

- set $\boldsymbol{H P}=\{h p: h p=1,2, \ldots, \overline{H P}\}$ - numbers of UTH points;

- set $S^{C}=\{s: s=1,2, \ldots, \bar{S}\}$, types of UMTs that are to transport goods from LCCs to UTHs;

- number of type $S$ UMT vehicles marked as value $n(s) \in N$;

- capacity of type $s$ UMT vehicles marked as value $\alpha(s) \in R^{+}$;

- set $\boldsymbol{M D}=\{d: d=1, \ldots, \bar{D}\}$ - types of UDVs that are to transport goods from the UTH directly to customers;

- number of type $d$ UDVs marked as value $n(d) \in N$;

- capacity of type $d$ UDV vehicles marked as value $\alpha 1(d) \in R^{+}$;

- set $\boldsymbol{U}=\{u(s): u(s)=1, \ldots, \overline{U(s)}\}$ services provided by the $s$ th UMTs;

- set $\boldsymbol{U d}=\{u d(d): u d(d)=1, \ldots, \overline{U d(d)}\}$ services provided by the $d$ th urban delivery vans;

- unit cost $k(u(s), s) \in R^{+}$of performing service $u(s)$ by vehicle $s$;

- unit cost $k 1(u d(d), d) \in R^{+}$of performing service $u d(d)$ by vehicle $d$;

- time $\tau c(u(s), s) \in R^{+} \cup\{0\}$ needed for unloading of type $s$ UMT vehicles at the $h p$ transshipment hub,

- time $\tau d(u d(d), d) \in R^{+} \cup\{0\}$ needed for unloading of type $d$ UDV vehicles at the $h p$ th transshipment hub;

- maximum number of UMTs served simultaneously at the UTH, marked as $n^{c}(h p, s) \in N$;

- maximum number of UDVs served simultaneously at the UTH, marked as $n^{d}(h p, d) \in N$.

Most of the customers are business entities with known characteristics, so we assume that we have

- a set of $J=\{1,2, \ldots, i, j, \ldots \bar{J}\}$ numbers of customers served by the distribution system designed;

- set of $L^{j}=\left\{l: l=1,2, \overline{L^{j}}\right\}$ types of goods delivered to the $j$ th customer from the LCC;

- set of $L^{h p}=\left\{l: l=1,2, \overline{L^{h p}}\right\}$ types of goods delivered to the $h p$ th UTH;

- vector $z^{l}=[q(l, 1), \ldots, q(l, j), \ldots, q(l, \bar{J}]$ of customers' potential orders for $l$ type goods;

- values $q(l, j)$ with the interpretation of the volume of the order for the $l$ th type of merchandise at the $j$ th customer;

- values $q(l, h p)$ with the interpretation of the volume of the order for the $l$ th type merchandise at the $h p$ th hub;

- value $\left[t^{a}(j), t^{b}(j)\right]$ with the interpretation of the time interval in which the carriage to the $j$ th customer is to be executed;

- value $t(j) \in \boldsymbol{T}$ with the interpretation of the time interval number $t$ in which the order of the $j$ th customer is to be executed;

- value $\tau^{j}(l, j, d) \in R^{+} \cup\{0\}$ with the interpretation of the time needed for unloading the $d$ th vehicle with the $l$ th merchandise at the $j$ th customer. 
In most cases, the planning includes, from several hours to half-a-day, so each period should also be relatively short, for example, of the order of a quarter or half an hour. It has been assumed at the same time that in the period not more than one departure of the sth vehicle to the UTH may occur and the period length is a multiple of the unloading time of a UMT-type vehicle.

\subsection{Service model formalization}

The urban logistic service model presented in this paper is a result of the work on the development project [5], and it is also patterned after the work [9]. Generally, the problem of the urban logistic service can be written as follows.

For the assigned sets $\boldsymbol{C C}, \boldsymbol{H P}, \boldsymbol{J}$ and the sets of characteristics of transport means $\mathbf{S}^{\mathbf{c}}, \boldsymbol{M D}, \boldsymbol{U}, \boldsymbol{U d}$, as well as the sets of characteristics of transition points, the following must be determined:

$$
\begin{gathered}
\forall u(s) \in U x(u(s))=\left\{\begin{array}{ll}
1 & \text { when an urban motor truck provides type } u(s) \text { service } \\
0 & \text { in other cases }
\end{array},\right. \\
\forall u d(d) \in U d y(u d(d))= \begin{cases}1 & \text { when an urban delivery van provides type } u d(d) \\
0 & \text { in other cases }\end{cases}
\end{gathered}
$$

while taking into account, among other things, limitations related to:

- non-exceeding of the load capacity of $s$-type vehicles in a single course

$$
\forall u(s) \in U \sum_{l \in L^{h p}} \sum_{h p \in H P^{*}} q(l, h p) \leq a(s) x(u(s)),
$$

where $\boldsymbol{H P}^{*}$ is the set of hubs served at the particular course

- non-exceeding of the load capacity of type $d$ urban motor vehicles

$$
\forall u d(d) \in U d \sum_{l \in L^{j}} \sum_{j \in J^{*}} q(l, j) \leq \alpha 1(d) y(u d(d)),
$$

where $\boldsymbol{J}^{*}$ is the set of recipients served at the particular course

- the work of UTHs and the condition of non-exceeding the transshipment capacities in a specified time interval:

- in the case of UMTs of the $s$ type

$$
\forall h p \in H P \forall t \in T \sum_{t^{*}=t-\tau(s)+1}^{t} \sum_{u(s) \in U}(u(s)) \leq n c(h p, s),
$$

- in the case of urban delivery vans of the $d$ type

$$
\forall h p \in H P \forall t \in T \sum_{t^{*}=t-\tau d(d)+1}^{t} \sum_{u(s) \in U} y(u d(d)) \leq n d(h p, d),
$$

- limitation to the number of $s$-type vehicles owned

$$
\forall s \in S^{c} \sum_{u(s) \in U} x(u(s)) \leq n(s),
$$

- limitation to the number of $d$-type vehicles owned

$$
\forall d \in M D \sum_{u d(d) \in U d} y(u d(d)) \leq n(d),
$$


So that the function of criterion of the interpretation of the total system operation cost being a total of the costs generated by UDV vehicles of the $s$ type and UMT vehicles of the $d$ type

$$
\left[\sum_{s \in S^{c}} \sum_{u d(d) \in U d} k(u(s), s) x(u(s))+\sum_{d \in M D} \sum_{u d(d) \in U d} k 1(u d(d), d) y(u d(d))\right],
$$

achieved the minimum value.

Objective function and constraints clearly define the use of linear programming to solve the model.

\section{APLLICATION OF THE MODEL TO OPTIMIZATION OF LOGISTICS SERVICE OF SELECTED WARSAW DISTRICT}

\subsection{Transport service optimization}

The case study is related to the optimization of the provision of refreshing drinks from different suppliers of shops located in Warsaw. It has been assumed that the LCCs for this merchandise are located in the outskirts of the city, at main exit roads to the north, south, east, and west. The merchandise is delivered from the LCC to UTHs located in each of the 17 Warsaw districts. The deployment of LCCs and UTH's is presented in Fig. 5. The optimization was made for two-time horizons (two optimization variants) with a changing number of recipients in a particular district.

Variant 1 assumes an improvement in the routes currently applied. Then, in variant 2, the number of the goods recipients was increased from 15 to 20 shops. Due to the volume of the input data related to the number of recipients, optimization results are presented only for one district (Wawer). It has been assumed that the UTH for the district is supplied every day by LCC3 (see Fig. 5a. [10]).

The costs of the current transport service, resulting mainly from the number of vehicles used for delivery and the total length of the routes covered by them, have been compared with the same data obtained from the optimization. Additionally, for each variant, the cost of the monthly service of the region has been calculated with the assumption of a 6-day working week.

The data related to the currently operated routes for the transport service of shops in the Wawer district are presented in Table 1.

Optimization results for variants 1 and comparison 2 are presented in Tables 2 and 3. Table 4 presents the comparison of current with routes obtained in variants 1.

a)

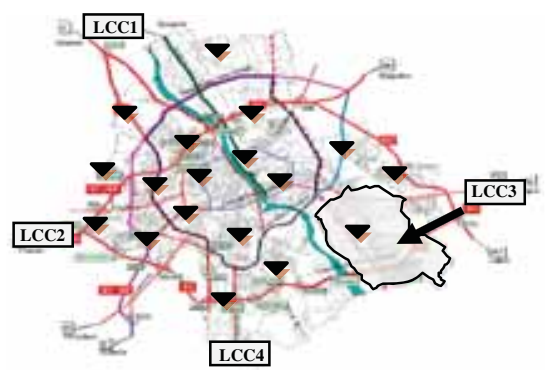

b)

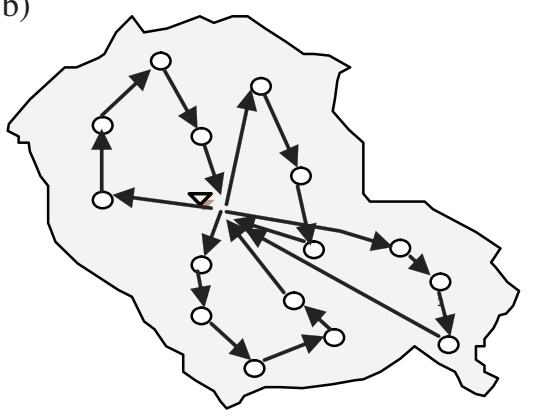

Figure 5: Graphic illustration of (a) the transport service region, (b) the current structure of the routes operated by the transport company. 
Table 1: Data for the currently operated routes for the transport service of shops in the Wawer district.

$\begin{array}{ll}\text { On-route } & \text { Total route } \\ \text { Route } & \text { ride time Unloading } \\ \text { covering }\end{array}$

Vehicle Monthly

Vehicle no. length [km] [min] time [min] time [min] use [\%] Cost [Euro] cost [Euro]

\begin{tabular}{llrrrrrr}
\hline $\mathbf{1}$ & 18.9 & 37 & 29 & 66 & 97 & 3.4 & 85 \\
$\mathbf{2}$ & 15.7 & 31 & 25 & 56 & 70 & 2.8 & 70 \\
$\mathbf{3}$ & 18 & 36 & 30 & 66 & 99 & 3.2 & 80 \\
$\mathbf{4}$ & 22.1 & 44 & 28 & 72 & 98 & 3.9 & 97.5 \\
Total & 74.7 & 148 & 112 & 260 & avg-91 & 13.3 & 332.5 \\
\hline
\end{tabular}

Table 2: Variant 1 of transport service optimization for the Wawer district.

\begin{tabular}{lccccccc}
\hline & $\begin{array}{c}\text { Route } \\
\text { Vehicle no. }\end{array}$ & $\begin{array}{c}\text { On-route } \\
\text { ride time } \\
\text { length [km] }\end{array}$ & $\begin{array}{c}\text { Unloading } \\
\text { time [min] }\end{array}$ & $\begin{array}{c}\text { Total route } \\
\text { covering } \\
\text { time [min] }\end{array}$ & $\begin{array}{c}\text { Vehicle } \\
\text { use [\%] }\end{array}$ & Cost [Euro] & $\begin{array}{c}\text { Monthly } \\
\text { cost [Euro] }\end{array}$ \\
\hline $\mathbf{1}$ & 17.4 & 34 & 30 & 64 & 98 & 3.1 & 77.5 \\
$\mathbf{2}$ & 16.1 & 32 & 22 & 54 & 71 & 2.8 & 70 \\
$\mathbf{3}$ & 17.8 & 35 & 30 & 65 & 97 & 3.2 & 80 \\
$\mathbf{4}$ & 20.8 & 42 & 30 & 72 & 98 & 3.7 & 92.5 \\
Total & 72.1 & 143 & 112 & 255 & avg-91 & 12.8 & 320 \\
\hline
\end{tabular}

Table 3: Variant 2 of transport service optimization for the Wawer district.

\begin{tabular}{lccccccc}
\hline & $\begin{array}{c}\text { Route } \\
\text { Vehicle no. }\end{array}$ & $\begin{array}{c}\text { On-route } \\
\text { ride time } \\
\text { length [km] }\end{array}$ & $\begin{array}{c}\text { Unloading } \\
\text { [mine [min] }\end{array}$ & $\begin{array}{c}\text { Total route } \\
\text { covering } \\
\text { time [min] }\end{array}$ & $\begin{array}{c}\text { Vehicle } \\
\text { use [\%] }\end{array}$ & $\begin{array}{c}\text { Monthly } \\
\text { Cost [Euro] }\end{array}$ & cost [Euro] \\
\hline $\mathbf{1}$ & 13.2 & 26 & 29 & 55 & 98 & 2.3 & 57.5 \\
$\mathbf{2}$ & 14.3 & 28 & 27 & 55 & 86 & 2.5 & 62.5 \\
$\mathbf{3}$ & 15.6 & 31 & 28 & 59 & 97 & 2.8 & 70 \\
$\mathbf{4}$ & 17.9 & 35 & 28 & 63 & 97 & 3.2 & 80 \\
$\mathbf{5}$ & 13.9 & 27 & 27 & 54 & 96 & 2.5 & 62.5 \\
$\mathbf{6}$ & 14.5 & 29 & 30 & 59 & 98 & 2.6 & 65 \\
Total & 89.4 & 176 & 169 & 345 & avg-95 & 15.9 & 397.5 \\
\hline
\end{tabular}

Variant 2 provides the optimization results in the situation where, on the same area as it was in variant 1 , the number of customers had increased. The results clearly indicate an increase in the total routes cost in comparison with variant 1 .

This is mainly due to the location of additional customers and additional number of vehicles required to serve them all. Nevertheless, it is worth noting that in addition to the cost increase, the 
Table 4: Comparison of current routes and routes obtained in variant 1.

\begin{tabular}{|c|c|c|c|c|c|c|c|}
\hline Variant no. & $\begin{array}{c}\text { Route } \\
\text { length }[\mathrm{km}]\end{array}$ & $\begin{array}{c}\text { On-route } \\
\text { ride time } \\
\text { [min] }\end{array}$ & $\begin{array}{l}\text { Unloading } \\
\text { time [min] }\end{array}$ & $\begin{array}{c}\text { Total route } \\
\text { covering } \\
\text { time [min] }\end{array}$ & $\begin{array}{c}\text { Avg. } \\
\text { vehicle } \\
\text { use [\%] }\end{array}$ & Cost [Euro] & $\begin{array}{c}\text { Monthly } \\
\text { cost [Euro] }\end{array}$ \\
\hline current & 74.7 & 148 & 112 & 260 & 91 & 13.3 & 332.5 \\
\hline 1 & 72.1 & 143 & 112 & 255 & 95 & 12.8 & 320.5 \\
\hline Difference & 2.6 & 5 & _- & 345 & - & 0.5 & 12.5 \\
\hline
\end{tabular}

Calculations obtained for variant 1 were aimed to present benefits of computer application usage for the vehicles routing. Due to the reorganization of customer service sequence in variant 1 , the total vehicles' routes length has got reduced which has a direct impact on reducing the total cost of customer service.

average vehicle fill has increased from $91 \%$ in variant 1 to $95 \%$ in variant 2 . This is equivalent to the reduction of vehicles empty runs and thus more viable usage of vehicles.

\subsection{Parameters of cargo consolidation center}

Because of the importance of the problem of receiving goods and shipping them to customers, the parameters of CCC for specified size requirements were analyzed. In this paper, this kind of calculation for UHT was skipped. For the purposes of research, information and material streams flowing between the CCC and its counterparties are divided into:

- information streams preceding entry of cargo flows to CCC,

- information streams preceding leaving CCC by cargo flows,

- information streams accompanying cargo flows,

- cargo flows incoming to and outgoing from CCC,

- information streams occurring after cargo flows. This is information such as delivery/shipment manifesting, returns of certified waybills, and transferring them to appropriate functional areas, invoices for services.

It is assumed that CCC will serve two types of transport units:

1. Uniform palletized load unit (uplu) constructed on EUR-type pallets - will be delivered to the CCC from suppliers. Dimensions of this unit are 1200/800/1260, weighing up to $400 \mathrm{~kg}$.

2. Consolidated palletized load unit (cplu) constructed on EUR-type pallets - will be used to ship goods to the UTHs. Its dimensions are 1200/800/1450, weighing about $360 \mathrm{~kg}$.

Two variants of CCC design were analyzed:

a. Option 1 - in which goods are stored in a warehouse on the floor in only one tier. Storage capacity due to the volume of cargo stream entering warehouse includes input buffer and storageconsolidation area. Output buffer capacity is a result of the number of units leaving warehouse each day;

b. Option 2 - in which goods are stored in pallet racks of five levels, while order-picking is done from two lower levels. 
Measures and indicators calculated for both variants are summarized in Table 5.

Table 5: Measures and indicators characterizing CCC.

\begin{tabular}{|c|c|c|c|c|}
\hline \multirow[b]{2}{*}{ Parameter } & \multirow[b]{2}{*}{ Unit } & \multirow[b]{2}{*}{ Symbol } & \multicolumn{2}{|c|}{ Point-wise element } \\
\hline & & & Option 1 & Option 2 \\
\hline \multicolumn{5}{|l|}{ Facility characteristics } \\
\hline Annual entrance volume & uplu & $P_{W E}^{R}$ & 59200 & 59200 \\
\hline Number of working days per year & days & $d_{r}$ & 305 & 305 \\
\hline $\begin{array}{l}\text { Daily material flow amassment on } \\
\text { entrance }\end{array}$ & - & $\varphi_{W E}$ & 1,2 & 1,2 \\
\hline Reliable daily entrance volume & uplu & $\lambda_{W E}^{D}$ & 230 & 230 \\
\hline $\begin{array}{l}\text { Daily material flow amassment } \\
\text { on exit }\end{array}$ & - & $\varphi_{W Y}$ & 1,4 & 1,4 \\
\hline Order-picking degree & - & $\tau$ & 1.0 & 1.0 \\
\hline Average fulfillment of picked pallet & - & $\rho$ & 0,6 & 0,6 \\
\hline Average structure of picked pallets & - & $w \cdot p$ & $14 \times 5$ & $14 \times 5$ \\
\hline $\begin{array}{l}\text { Number of articles to be } \\
\text { order-picked }\end{array}$ & - & $A$ & 216 & 216 \\
\hline Output standard & days & $N$ & 3 & 3 \\
\hline Work-time utilization coefficient & - & $\varphi_{t}$ & $0,85-090$ & $0,85-090$ \\
\hline CCC storage area capacity & $\mathrm{pp}$ & $Z_{p}$ & 630 & 630 \\
\hline The total area of the warehouse & $\mathrm{m}^{2}$ & $F_{M}$ & 5500 & 3400 \\
\hline Warehouse cubic capacity & $\mathrm{m}^{3}$ & $V_{M}^{M}$ & 26400 & 20150 \\
\hline \multicolumn{5}{|l|}{ Costs and indicators } \\
\hline $\begin{array}{l}\text { Total annual maintenance costs, } \\
\text { including: }\end{array}$ & euro/year & $K_{U}^{R}$ & 290967,1 & 179012,9 \\
\hline - costs of infrastructure maintenance & euro/year & $K_{U B}^{R}$ & 268888,9 & 152777,8 \\
\hline - costs of equipment maintenance & euro/year & $K_{U W T}^{R}$ & 22078,22 & 26190,67 \\
\hline Total annual cost of labor, including: & euro/year & $K_{L}^{R}$ & 373244,4 & 386844,4 \\
\hline - costs of material handling & euro/year & $K_{L T}^{R}$ & 306444,4 & 288888,9 \\
\hline - costs of information processing & euro/year & $K_{L N}^{R}$ & 66800 & 97955,56 \\
\hline Total annual operating costs & euro/year & $K_{E}^{R}$ & 664211,6 & 565812,9 \\
\hline $\begin{array}{l}\text { Cost of transition average unit } \\
\text { through the system }\end{array}$ & euro/uplu & $\gamma_{k p}$ & 11,22 & 9,557778 \\
\hline Participation of labor costs in total & - & $\gamma_{k L}$ & 0,56 & 0,68 \\
\hline $\begin{array}{l}\text { Participation of information } \\
\text { processing costs in total }\end{array}$ & - & $\gamma_{k N}$ & 0,22 & 0,34 \\
\hline
\end{tabular}




\section{CONCLUSIONS}

ICLS handles goods using CCCs and significantly affects the arrangement of the goods flow between the surroundings and customers located within the urban area.

The main objective of this paper was to prove the benefits of using CCC in ULS. The article shows delivery service in urban agglomeration on two-stage system in cooperation CCCs and UTHs.

Solutions based on a two-stage system with CCCs and UTH for ULS improving material flow in cities lead, among others, to:

- less traffic congestion in intercity movement,

- reduction of road infrastructure destruction,

- reduction of transport congestion in city centers,

- reduction of fumes emission and other pollution associated with vehicle movement.

The main conditions for establishing CCC to serve Polish urban agglomerations is awareness and responsibility of the manufacturers supplying goods to the metropolitan area and the carriers dealing with this issue through outsourcing. These entities must recognize benefits of partial cooperation with competitors rather than focusing on short-term profit.

The case study shows improvement of transport service organization in Wawer district. Optimization reduces the length of the total vehicles' routes. In large area and many roads optimization can reduce cost about few percentage per kilometer. Results are presented in Table 4. Moreover, variant 2, with increased number of customers, obtained better use of vehicle than in a current delivery strategy and variant 1 .

\section{REFERENCES}

[1] Crainic, T.G., Ricciardi, N., Storchi, G. Models for Evaluating and Planning City Logistics Transportation Systems. CIRRELT-2007.

[2] Jacyna M., The urban logistic service model in the aspect of the domestic logistic system. WIT Press Southampton, Boston-Urban Transport XVII - Urban Transport and the Environment in the 21st Centuru, str. 117-128, 2011.

[3] Bluszcz M., Jacyna M., Model Solutions for Interfaces of the Urban Logistic System with the Domestic Logistic System. Archives of Transport, Polish Academy of Sciences Committee of Transport, Warsaw, 21, pp. 5-24, 2009.

[4] Harris, C., Ullman, E., The nature of cities. Annals of the American Academy of Political Science, 242, pp. 7-17, 1945. doi: http://dx.doi.org/10.1177/000271624524200103

[5] Jacyna M., Report from Development Project on: The Model of the Logistic System of Poland as a Way to Transport Comodality in the European Union. Task 3 entitled Position of Urban Logistics in the Domestic Logistic System, 2011.

[6] Chmielewski J.M. Teoria urbanistyki w projektowaniu i planowaniu miast [Theory of Town Planning in Designing and Planning of Towns], Oficyna Wydawnicza Politechniki Warszawskiej, Warszawa 2001.

[7] Szołtysek J., Podstawy logistyki miejskiej [Rudiments of Urban Logistics], Wydawnictwo Akademii Ekonomicznej, Katowice 2000.

[8] Browne M., Allen S. And Woodbum: Urban Freight Consolidation Centres. In Recent Advances in City Logistics, eds Taniguchi E. And Thompson R.G. Elsevier: Amsterdam, pp. 253-265, 2006.

[9] Jacyna M. Modelowanie i ocena systemów transportowych. [Modelling and Assessment of Transport Systems], Oficyna Wydawnicza Politechniki Warszawskiej, Warszawa 2008.

[10] Chief Statistical Office, www.stat.gov.pl 